\title{
Very Good Partial Response in Neuroblastoma
}

National Cancer Institute

\section{Source}

National Cancer Institute. Very Good Partial Response in Neuroblastoma. NCI

Thesaurus. Code C103311.

Greater than 90\% reduction of primary tumor; no metastatic tumor (as above except bone); no new bone lesions, all pre-existing lesions improved on bone scan; HVA/VMA normal. 